\title{
Covid-19: Doctors still at "considerable risk" from lack of PPE, BMA warns
}

\section{Gareth lacobucci}

The BMJ

The BMA has warned that doctors are still being placed at "considerable risk" by shortages of personal protective equipment, despite government assurances that enough supplies are being delivered.

On 30 March the association said it was seeking urgent clarity from the government on what risks staff in hospitals and GP surgeries should and should not have to take if they didn't have adequate PPE. The move follows a warning last week that the shortage of PPE was unacceptable and was putting doctors' lives at risk. ${ }^{1}$

The warning was in response to the secretary of state for housing, communities, and local government, Robert Jenrick, saying at the government's daily briefing on 29 March that "we cannot and should not ask healthcare workers to be on the frontline without appropriate protective equipment," while emphasising that "millions" of masks, gloves, eye protectors, and gowns were being delivered.

But the BMA said it continued to receive reports over the weekend of 28-29 March of doctors and staff not having access to adequate PPE. One junior doctor reported, "I have asthma and had a recent chest infection. I fear that I am risking my health and life because adequate PPE has not been made available in my workplace."

A group of doctors working in Shropshire said, "Every single day we work on the respiratory ward and we have to enter a bay full of covid-19 positive patients multiple times while we feel unprotected. We have to walk out of the ward every day worrying that we may pass on covid to other negative patients merely due to the inadequacy of the PPE."

Rob Harwood, chair of the BMA's Consultants Committee, said that the safety of doctors and their patients must be protected.

He said, "While the government has been forthcoming in letting us know that protection is on the way, there are still doctors and other NHS staff who today, tomorrow, and in the coming week may face the daunting prospect of having to consider treating patients without adequate protection.

"Having seen the tragic deaths of medics in Italy and now closer to home here in the UK, doctors and NHS staff have every right to be concerned, knowing that a lack of adequate protection is not only dangerous, it may be fatal."

The BMA said it was also hearing of wide geographical variation in the PPE available to general practices.

A GP in Wolverhampton said, "Only this weekend myself and a colleague treated a child with a fever, in an urgent care setting with only a surgical mask, flimsy gowns, and gloves as per current PHE [Public Health England] advice. This is simply not safe. I know locally there is huge variability and availability of PPE. Some doctors are using hazmat suits with eye protection and respirators to see any symptomatic patients, whereas I am hearing that most GP practices are struggling to source even surgical masks."

Another GP said, "We've placed an order, it's been accepted, but they will only give us half of what we need and cannot tell us when it will be delivered."

Richard Vautrey, chair of the BMA's General Practitioners Committee, said, "Despite the promises about the urgent delivery of personal protective equipment, the reality for many practices on the ground remains the same.

"This situation cannot be allowed to continue. Practices need action, not more promises."

Newman M. Covid-19: doctors' leaders warn that staff could quit and may die over lack of protective equipment. BMJ 2020;368:m1257. 10.1136/bmj.m1257 32217522

Published by the BMJ Publishing Group Limited. For permission to use (where not already granted under a licence) please go to http://group.bmj.com/group/rights-licensing/ permissions 